\title{
LA ARQUITECTURA BOLIVIANA DE LA REVOLUCIÓN DEMOCRÁTICA Y CULTURAL
}

\section{Micaela Ugarte y Juan E. Cabrera}

\section{RESUMEN}

Este trabajo presenta una primera aproximación a las características de la arquitectura estatal producida por el Estado boliviano durante el periodo 2006 a 2019 conocido como el "Proceso de Cambio" o la "Revolución Democrática y Cultural". Tiene el objetivo de caracterizar la arquitectura producida por el Estado boliviano en comparación con códigos de la arquitectura revolucionaria de otros países, así como códigos y rasgos propios de las culturas prehispánicas de la región. El artículo examina referencias de arquitectura de otras revoluciones, revisa las características de evolución del "Proceso de Cambio", observa las condiciones del escenario urbano boliviano, analiza una serie de hechos arquitectónicos usando el enfoque trilógico y finalmente caracteriza las principales edificaciones estatales según códigos y rasgos que coincidirían con el discurso revolucionario y el nuevo paradigma del "Vivir Bien". La revisión y reflexión final corrobora una limitada coincidencia de la práctica arquitectónica con el discurso revolucionario y parece ratificar la noción de que la arquitectura revolucionaria es más un producto de mercado.

Palabras Clave: Arquitectura, Arquitectura Estatal, Bolivia, Revolución Democrática Cultural.

DOI: 10.23881/idupbo.020.2-9e 